\title{
Aproximaciones etNobotánicas de las especies y PRÁcticas de frutos nativos comestibles de la actualidad. Aportes para la inTERPRETACIÓn del PASAdo PREHISPÁNICO de CERro Colorado (Córdoba, Argentina)
}

\author{
VALENTINA SAUR PALMIERI ${ }^{1 *}$, MARÍA LAURA LÓPEZ² y CECILIA TRILLO1
}

\begin{abstract}
Summary: Ethnobotanical approaches of edible native fruits' species and practices of the present. Contributions for the interpretation of the Late Pre-Hispanic Period of Cerro Colorado (Córdoba, Argentina). Ethnobotanical research provides important information from the present upon which paleoethnobotany, a discipline that interprets archaeobotanical remains, stands in order to infer possible uses and practices performed in the past by human groups. This study aimed to, first, identify and document native plant species producing edible fruits currently used by the residents of Cerro Colorado and surrounding areas (Córdoba, Argentina). In second place, it intended to detail practices associated with their use as food (preharvest, harvest, postharvest, consume, discard). In order to achieve both objectives, open and semi-structured interviews and participant observation were performed. As last objective, by evaluating the obtained results, this work tried to approach to the different activities' spheres where vegetables are implied, which could have occurred in the past A total of 20 species whose fruits are recognized as food were identified, 13 of them are processed somehow before being consumed and the rest are ingested raw, just as "fresh fruit". Besides, several products were registered such as arrope, jam, jelly and flour prepared from edible fruits. For the archaeologic analysis, information from Quebrada Norte 7 site (Sierra del Norte, Córdoba) is available. Data integration let us perceive actual postharvest practices that probably correlate with past practices, and the existence of discontinuation of wild resources consuming forms.
\end{abstract}

Key words: North of Córdoba, paleoethnobotany, Chaco resources, edible plants, traditional practices.

\begin{abstract}
Resumen: Los estudios etnobotánicos constituyen una importante base de conocimiento sobre la cual la paleoetnobotánica, disciplina que analiza los restos vegetales arqueológicos, hace pie para inferir las posibles prácticas realizadas en el pasado por los grupos humanos. El presente trabajo tiene como objetivo, en primer lugar, identificar y documentar las especies nativas de frutos comestibles utilizadas por los pobladores actuales de Cerro Colorado (Córdoba, Argentina) y alrededores. En segundo lugar, detallar las prácticas asociadas a su uso como alimento (precolecta, colecta, postcolecta, consumo y descarte). Para ambos objetivos se efectuaron entrevistas abiertas y semiestructuradas y observación participante de las actividades realizadas. $Y$ finalmente, mediante los resultados obtenidos, realizar un primer acercamiento a las distintas esferas de actividades que pudieron realizarse en el pasado y en los cuales estuvieron involucradas los vegetales. De esta manera, se contabilizaron 20 especies cuyos frutos se reconocen como alimento, de los cuales 13 son procesados de algún modo antes de ser consumidos, mientras que el resto son ingeridos únicamente como "fruta fresca". Se registraron diversos productos, tales como arrope, mermelada, jalea y harina. Para el estudio de lo ocurrido en el pasado, se cuenta con la información proveniente del sitio Quebrada Norte 7 (Sierra del Norte, Córdoba). La integración de datos permitió vislumbrar prácticas postcolecta actuales que pueden tener su correlato en el pasado, como así también la existencia de discontinuidades en el consumo de los recursos nativos.
\end{abstract}

Palabras clave: Norte cordobés, paleoetnobotánica, recursos chaqueños, plantas alimenticias, prácticas tradicionales.

\footnotetext{
${ }^{1}$ Cátedra de Diversidad Vegetal II-Departamento de Diversidad Biológica y Ecológica, FCEFyN, UNC.

${ }^{2}$ CONICET-División Arqueología, Laboratorio 129, FCNyM, UNLP.

*altea345@hotmail.com
} 


\section{INTRODUCCIÓN}

El contexto cultural, modo de ver e interpretar el mundo, determina el vínculo que los seres humanos poseen con su entorno (Hurrell \& Albuquerque, 2012). En este sentido, el presente trabajo se enmarca dentro de la Etnobotánica, la cual constituye el estudio de la interrelación de las sociedades humanas con las plantas en el presente (Ford, 1978; Hurrell \& Albuquerque, 2012) y se deriva en la Paleoetnobotánica ${ }^{3}$, disciplina que tiene por objetivo caracterizar dicha relación en el pasado (Hastorf, 1999; Lema, 2011; Pearsall, 2016). La primera de ellas se aborda a partir de análisis etnográficos de comunidades actuales (mediante entrevistas y observaciones participantes), mientras que la segunda se realiza a partir del análisis y la interpretación del material arqueobotánico. Para ello se recurre a los datos provenientes de la etnobotánica, la etnoarqueología y los estudios experimentales (Hillman, 1973, 1984; Buxó, 1997; Capparelli \& Lema, 2011).

Un aspecto fundamental de la Etnobotánica/ Paleoetnobotánica es el denominado Conocimiento Ecológico Tradicional (CET). Éste es el conjunto de conocimientos, prácticas y creencias que las personas poseen acerca de los modos de relacionarse de los seres vivos (incluidos los seres humanos) entre sí y con su entorno. El término "Tradicional" denota que el CET se acumula y transmite de generación en generación, pero no hace referencia a inflexibilidad o inalterabilidad, por el contrario, es dinámico y adaptable a cambios en ese ambiente donde se desarrolla y a la experiencia histórica del grupo humano que lo posee (Berkes, 1999; Berkes et al., 2000; Ferreira Júnior et al., 2015). Por esta razón, la profundidad temporal no es condición sine qua non del CET como sí

\footnotetext{
${ }^{3}$ En este trabajo nos referiremos a Paleoetnobotánica siguiendo el acuerdo establecido en la $4^{\circ}$ Reunión Internacional de Teoría Arqueológica en América del Sur, en el cual se determinó que dicho término hace referencia al estudio de la relación comunidad humanacomunidad vegetal en el pasado. En otro sentido, el vocablo Arqueobotánica alude al estudio de restos botánicos a fin de desentrañar cuestiones de índole puramente arqueológicas, es decir, la relación sociedad humana-sociedad humana en la cual las plantas fueron sólo un instrumento (Giovanetti et al., 2008).
}

lo es su carácter comunal; es decir, es gestado, reproducido, transformado y reconocido por los miembros de la comunidad aunque no provenga del pasado remoto (Pochettino \& Lema, 2008). Según Hurrell \& Albuquerque (2012), el conocimiento se materializa en acciones y prácticas que a su vez contribuyen a la evolución del CET. Las prácticas agrícolas, la preparación de alimentos, el cuidado de la salud, la conservación y las actividades que permiten el mantenimiento de un determinado grupo en un ambiente, dado forman parte del CET (Pochettino \& Lema, 2008; Trillo et al., 2010).

Analizando el CET que los pobladores actuales del territorio cordobés poseen en relación a los productos silvestres disponibles en los ambientes naturales que los rodean, se observa que los frutos nativos chaqueños ya no constituyen la base de la alimentación de la mayoría de las personas (Arias Toledo, 2008). Sin embargo, existe una profunda documentación etnobotánica del uso de estos recursos en la provincia en décadas pasadas. Río \& Achával (1905) mencionan 20 especies comestibles, y diversos productos obtenidos de las mismas, a principios del siglo XX. La persistencia a lo largo de los últimos 100 años del uso de la mayoría de las especies referenciadas son documentadas en la actualidad en diversos trabajos etnobotánicos (Arias Toledo et al., 2007; Arias Toledo, 2008; Trillo et al., 2014; Trillo, 2016). Similares resultados se han encontrado en provincias vecinas como La Rioja (Biurrun et al., 2007) y Santiago del Estero (Di Lullo, 1935). En los trabajos citados se menciona que estos frutos son consumidos de diversas maneras: algunos son ingeridos como fruta fresca y otros son procesados con el fin de elaborar arropes, mermeladas, bebidas, condimentos y harinas.

En la Provincia de Córdoba en la última década, las investigaciones de índole arqueobotánico que se implementaron en el sector serrano han permitido identificar vegetales que fueron incluidos dentro de la alimentación por los grupos humanos prehispánicos. Fueron hallados macrorrestos (frutos y semillas) carbonizados y microrrestos (almidones y silicofitolitos) de frutos silvestres y domésticos, junto a las posibles prácticas realizadas con los mismos (López, 2015). No obstante, los análisis que pretenden determinar las prácticas postcolecta 


\section{Saur Palmieri et al. - Especies y prácticas de frutos comestibles en Cerro Colorado}

son iniciales, debido principalmente a la falta de datos específicos provenientes de la etnobotánicaetnoarqueología ${ }^{4}$ (sensu Lema, 2009) que traten sobre los recursos chaqueños como así también a la escasez de restos vegetales arqueológicos recuperados en los diferentes sitios. Los primeros estudios en esta línea de investigación en la provincia se han desarrollado con algarrobo blanco (Prosopis alba Griseb., Fabaceae) y negro (P. nigra (Griseb) Hieron., Fabaceae) estableciendo una comparación entre los residuos de procesamiento postcolecta con los algarrobos blanco (P. chilensis (Mol.) Stuntz., Fabaceae) y negro (P. flexuosa DC, Fabaceae) del valle de Hualfín (Catamarca) (López \& Capparelli, 2014). Asimismo, algunos avances se lograron con el mistol (Sarcomphalus mistol (Griseb.) Hauenschild, Rhamnaceae) aunque los resultados requieren de mayor profundización para poder aplicarlos al registro arqueobotánico (López et al., 2015).

Por todo lo expuesto, el objetivo de este trabajo es describir la relación existente entre las especies vegetales de frutos comestibles y los pobladores actuales de Cerro Colorado a través del estudio de las prácticas pre y post-colecta asociadas a los frutos silvestres comestibles a fin de generar la base de datos etnobotánicos para la interpretación futura de carporrestos arqueológicos de especies chaqueñas. Se hipotetiza que las prácticas post colecta asociadas al consumo de los vegetales silvestres reflejan una continuidad desde tiempos prehispánicos hasta la actualidad, aun cuando se observen ciertos cambios propios del devenir del CET.

\section{Materiales y Métodos}

\section{Área de estudio}

El área de estudio está constituida por cuatro localidades del noroeste de la Provincia de Córdoba: Cerro Colorado $\left(30^{\circ} 05^{\prime} 49^{\prime \prime} \mathrm{S}, 63^{\circ} 55^{\prime} 52^{\prime \prime} \mathrm{W}\right)$, Rayo

\footnotetext{
${ }^{4}$ Etnoarqueología es una subdisciplina de la arqueología y de la antropología social que obtiene información sistemática de los trazos material de la conducta humana y cuyo trabajo de campo es encarado con sociedades actuales, pero desde una mirada arqueológica (Politis, 2004). El complemento Etnobotánica-Etnoarqueología hace al estudio del registro material dejado por las personas tras la toma de decisiones en las actividades desarrolladas y en la cual se involucra a las plantas.
}

Cortado (3004'26”S, 6349'26”'W), Quebrada Norte $\left(30^{\circ} 03^{\prime} 49^{\prime \prime} \mathrm{S}, 63^{\circ} 55^{\prime} 05^{\prime \prime} \mathrm{W}\right)$ y El Rincón $\left(30^{\circ} 05^{\prime} 57^{\prime} \mathrm{S}, 63^{\circ} 57^{\prime} 18^{\prime \prime} \mathrm{W}\right)$ (Fig. 1); las tres primeras pertenecen al Departamento Río Seco y la última al Dpto. Tulumba.

Esta zona pertenece al Distrito Chaqueño Serrano de la Provincia Fitogeográfica Chaqueña según Cabrera (1976) y a la Ecorregión del Chaco Seco según Burkart et al., (1999). Además, está ubicada dentro del dominio climático semi-seco (Capitanelli, 1979), donde las precipitaciones disminuyen del este del sistema serrano $(600 \mathrm{~mm}$ anuales) al oeste (menos de $500 \mathrm{~mm}$ anuales). La temperatura media anual aumenta en sentido contrario, con valores que oscilan entre los $18,6^{\circ} \mathrm{C}$ al este y los $19,9^{\circ} \mathrm{C}$ al oeste) (Cabido \& Zak, 1999). La región comprende el ecotono entre el bosque serrano ubicado hacia el oeste y el bosque chaqueño de llanura hacia el este. El primero, se caracteriza por la presencia de molle de beber (Lithraea molleoides (Vell.) Engl., Anacardiaceae), mato (Myrcianthes cisplatensis (Cambess.) O. Berg, Myrtaceae) y piquillín (Condalia montana A. Cast., Rhamnaceae) (Sayago, 1969; Paván, 2012). En el segundo, existen comunidades de especies semideciduas en las que se destaca el quebracho blanco (Aspidosperma quebracho-blanco Schltdl., Apocynaceae) y el cardón (Stetsonia coryne (SalmDyck) Britton \& Rose, Cactaceae). La fisonomía que predomina en este sistema serrano es la de bosque cerrado a semi-cerrado con un 60 a $80 \%$ de cobertura arbórea, de entre 7 y $12 \mathrm{~m}$ de altura, pudiéndose encontrar en el sector norte ejemplares de orco quebracho (Schinopsis lorentzii (Griseb.) Engl., Anacardiaceae) de más de 15 m (Cabido \& Zak, 1999).

\section{Contexto sociocultural}

Los pobladores del noroeste de la provincia de Córdoba se consideran a sí mismos "criollos" (Trillo, 2010). Son producto del contacto entre españoles y grupos étnicos locales, son católicos e hispanoparlantes que realizan actividades relacionadas al cuidado del ganado, agricultura de subsistencia y producción textil (Trillo et al., 2014). Además, complementan la actividad productiva agropecuaria tradicional con actividades comerciales y de venta de servicios, como el turismo y las artesanías (Cáceres, 2003; Torrico Chalabe \& Trillo, 2015). Esta zona de la provincia de Córdoba 


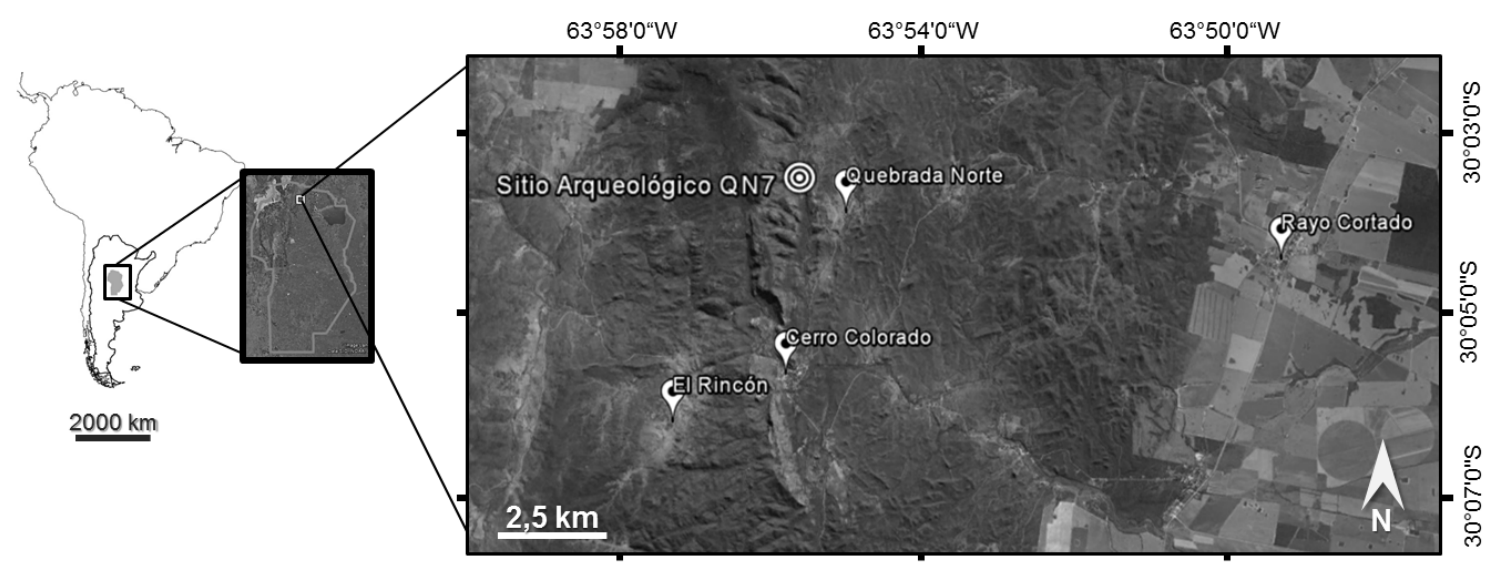

Fig. 1. Ubicación del área de estudio. Cerro Colorado, El Rincón, Quebrada Norte y Rayo Cortado, localidades ubicadas al noroeste de la provincia de Córdoba, Argentina. Se observa ubicación del Sitio Arqueológico (QN7) en el cual se están desarrollando estudios arqueobotánicos (Recalde, 2015; López, 2016; López \& Recalde, 2016; Recalde \& López, 2017). Imagen satelital obtenida del Software Google Earth (julio de 2017).

pertenece a la denominada región extra-pampeana de la República Argentina, caracterizada por un menor desarrollo capitalista relativo en relación al área pampeana (Ahumada \& Trillo, 2017).

Particularmente, la localidad de Cerro Colorado, según datos del Censo Nacional de Población, Hogares y Viviendas (INDEC, 2010), cuenta con 285 habitantes, de los cuales 60 se encuentran dispersos en el área rural cercana a la localidad. La actividad económica de los pobladores de la comuna se distribuye entre la ganadería familiar a pequeña y mediana escala, el empleo en pequeños comercios, el empleo público, el turismo y la fabricación de productos artesanales y manufacturas (Arias Toledo, 2008, 2009). Sin embargo, la tasa de desocupación asciende a 2,4 (siendo 4,9 para la totalidad del departamento).

Por otro lado, la comuna de Cerro Colorado es la puerta de entrada a la Reserva Natural y Cultural homónima. La misma abarca unas 3000 ha, albergando y protegiendo 45 sitios arqueológicos con arte rupestre de sociedades prehispánicas locales (Recalde, 2015) y bosques de mato y molle de beber. Uno de los sitios más estudiados de la zona es Quebrada Norte 7 (QN7). Emplazado a $5 \mathrm{~km}$ al norte de la localidad de Cerro Colorado, éste es a cielo abierto, y se caracteriza como residencial multipropósito o poblado tardío prehispánico (Recalde, 2015; Recalde \& López,
2017). Fue cronológicamente ubicado en el Período Prehispánico Tardío (1500-300 AP, cal. ca. 4001550 AD) a partir de dos dataciones: $1250 \pm 80$ años A.P. (ca. 700 AD; carbón- LP-3212) y $405 \pm$ 21 A.P. (ca. 1500 AD; maíz- AA107245) (Recalde \& López, 2017). Las excavaciones realizadas permitieron recuperar una alta densidad de material arqueológico. Los artefactos líticos, entre los que se registran instrumentos de molienda, puntas de proyectil y desechos de talla, se asocian a fragmentos de cerámica, relacionados principalmente a cuencos y ollas de uso cotidiano, dando cuenta de actividades de índole residencial doméstica. En referencia a los recursos de subsistencia, los restos faunísticos evidencian especies de la familia Cervidae, del género Lama -guanaco o llama-, Cavia -cuises-, Rhea -ñandú- y la especie Chaetophractus villosus Desmarest, 1804 -quirquincho-), mientras que los botánicos se corresponden con taxa silvestres, presentes en la zona, y con domesticadas junto a malezas (Recalde \& López, 2017). Entre los primeros, se encuentra el mistol, chañar (Geoffroea decorticans (Gillies ex Hook. \& Arn.) Burkart, Fabaceae), molle de beber, piquillín (Condalia sp., Rhamnaceae), algarrobo (Prosopis sp.) y aguaribay (Schinus cf. areira L., Anacardiaceae), y entre los segundos el maíz (Zea mays L., Poaceae), poroto (Phaseolus cf. vulgaris, Fabaceae), quinoa (Chenopodium 


\section{Saur Palmieri et al. - Especies y prácticas de frutos comestibles en Cerro Colorado}

quinoa Willd. var. quinoa, Chenopodiaceae), ajara (C. quinoa Willd. cf. var. melanospermum Hunz., Chenopodiaceae) y amaranto (cf. Amaranthus sp., Amaranthaceae) (López, 2017). Es importante aclarar que, de los sitios excavados en el área arqueológica de Cerro Colorado, QN7 es el único donde se recuperaron carporrestos, constituyéndose a su vez en el sitio donde mayor cantidad de restos botánicos macroscópicos han sido encontrados dentro de la provincia de Córdoba (López, 2017; Recalde \& López, 2017).

\section{Muestreo etnográfico}

En el primer acercamiento a la comuna de Cerro Colorado se conversó con el Guardaparque de la Reserva Natural y Cultural y con el encargado de Turismo, quienes recomendaron a las primeras personas para entrevistar. Posteriormente, para conocer los frutos nativos utilizados como alimento se realizaron entrevistas abiertas (en la etapa exploratoria de la investigación (Padua, 1994) y semiestructuradas (Bernard, 1995) a informantes clave seleccionados a través de la técnica de "bola de nieve" (Guber, 1991; Martin, 1995; Aguilera et al., 2003). Se entrevistaron en total 11 personas: cinco de Cerro Colorado, tres de El Rincón, dos de Rayo Cortado y una de Quebrada Norte. En todos los casos, se obtuvo el consentimiento previamente informado de los colaboradores, en forma oral.

Las entrevistas definitivas fueron elaboradas en base a las entrevistas abiertas iniciales y bibliografía relacionada (Arenas, 1995, 2003; Capparelli \& Lema, 2011). Estas fueron acompañadas con un muestrario fotográfico de las 30 especies nativas de frutos comestibles presentes en el área, confeccionado a partir de revisión bibliográfica de trabajos etnobotánicos (Di Lullo, 1935; Biurrun et al., 2007; Arias Toledo, 2008; Rapoport et al., 2009; Trillo et al., 2014; Toledo et al., 2015; Trillo, 2016) y fitogeográficos (Sayago, 1969; Giorgis et al., 2011; Paván, 2012). Para la denominación de las especies se utilizó como referencia el "Catálogo de las Plantas Vasculares del Cono Sur" (Instituto de Botánica Darwinion, 2017).

Las distintas prácticas registradas se analizaron en términos de precolecta, colecta, postcolecta y consumo como proponen Capparelli \& Lema (2010) para el análisis de las actividades humanas en relación a las plantas útiles en el marco de estudios paleoetnobotánicos. La primera categoría incluye las prácticas de protección -cuidados destinados a la eliminación de competidores y depredadores, aplicación de fertilizantes, podas, protección contra heladas, etc. -, tolerancia -que consiste en mantener dentro de ambientes antropogénicos, plantas útiles que existían antes de que el ambiente fuera transformado por el humano-, fomento estrategias dirigidas a aumentar la densidad de población de especies útiles-, erradicación, cultivo, domesticación -proceso evolutivo que resulta de manipular los genotipos de las plantas- (Casas, 2001; Casas et al., 2016). La colecta comprende las distintas técnicas de recolección y cosecha, mientras que postcolecta engloba las actividades de transporte, almacenamiento, procesamiento (i.e. molienda, hervido, tostado, aventeado, secado, cocción). Por último, con el término consumo se denomina a las prácticas que marcan el fin último de la utilización (Capparelli \& Lema, 2010; López, 2015), en este caso la ingesta del fruto. Por otro lado, el instrumental utilizado se clasificó de acuerdo a Mauss (2006), quien plantea que una herramienta consiste en una única pieza de materia, mientras que un instrumento propiamente dicho es combinación de herramientas (o elementos) y una máquina se constituye de combinación de instrumentos.

La información recabada fue ordenada en tablas confeccionadas con el Software Excel de Office y se expresó en frecuencia absoluta y porcentaje de menciones por especie y por producto elaborado y conocido (Padua, 1994; Ahumada \& Trillo, 2017).

\section{Resultados y Discusión}

Utilización de frutos nativos comestibles por los pobladores de Cerro Colorado y alrededores en la actualidad

Especies

Los entrevistados de Cerro Colorado y alrededores reconocieron como comestibles los frutos de 20 especies vegetales nativas, dando cuenta de un $67 \%$ del total de taxa con dicha característica presentes en la región (Tabla 1). De éstas, 8 especies fueron citadas por la totalidad de los pobladores reflejando un alto consenso en relación con su uso (Tabla 1). Las 12 restantes fueron reconocidas únicamente por un individuo o por un grupo de ellos. Del total de recursos citados, 


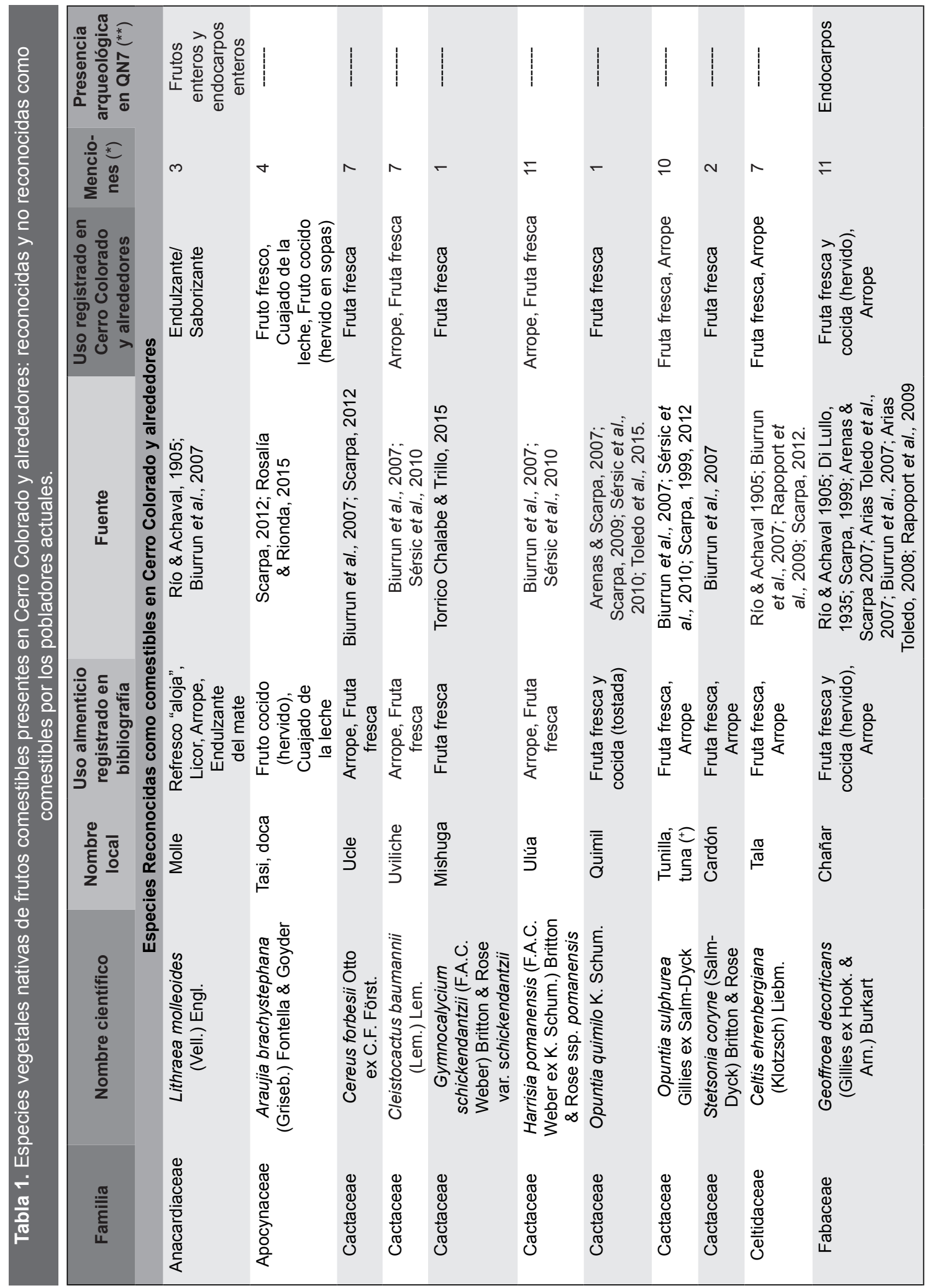




\begin{tabular}{|c|c|c|c|c|c|c|c|c|c|}
\hline 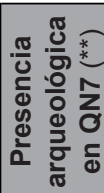 & 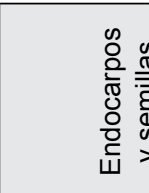 & 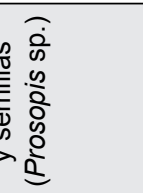 & 1 & 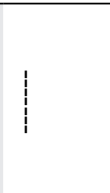 & 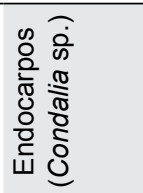 & 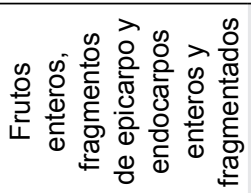 & & 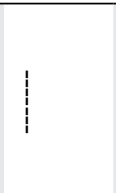 & \\
\hline 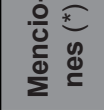 & $F$ & $F$ & N & 0 & $F$ & $\mp$ & $F$ & $\nabla$ & $\mp$ \\
\hline 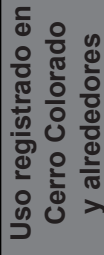 & 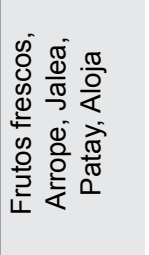 & 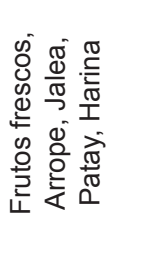 & 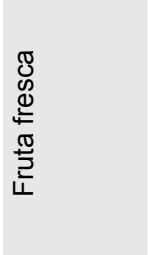 & 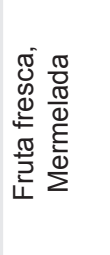 & 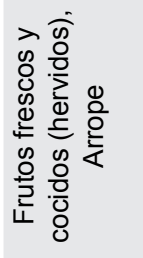 & 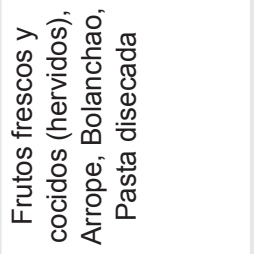 & 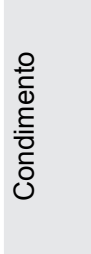 & 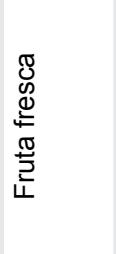 & 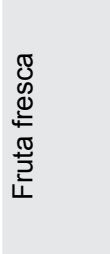 \\
\hline 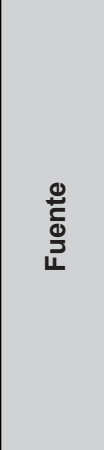 & 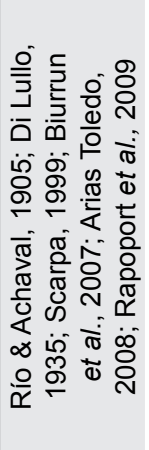 & 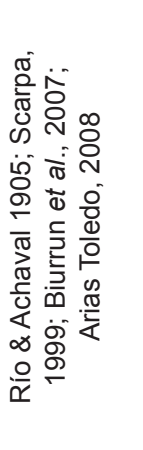 & 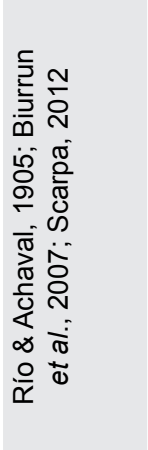 & 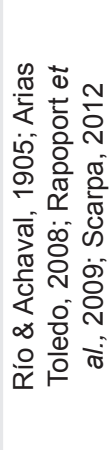 & 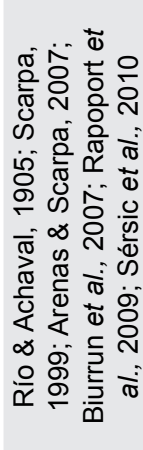 & 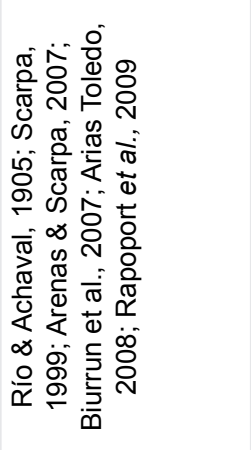 & 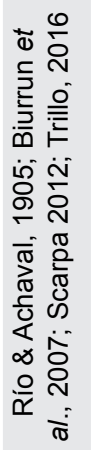 & 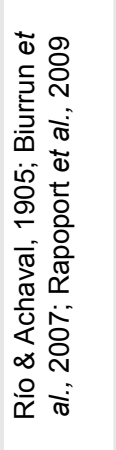 & 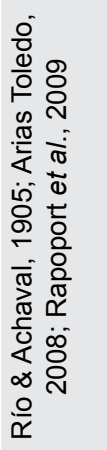 \\
\hline 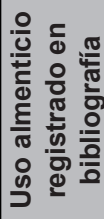 & 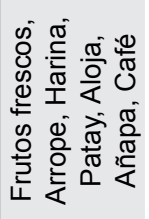 & 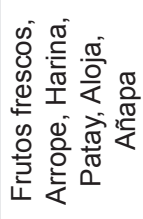 & 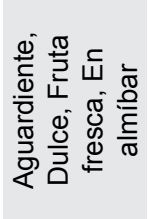 & 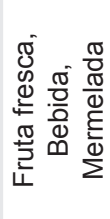 & 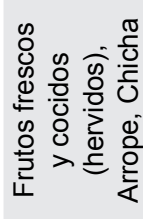 & 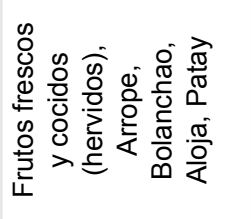 & $\begin{array}{l}\frac{0}{1} \\
\frac{1}{0} \\
\frac{E}{\overline{0}} \\
\overline{0} \\
0\end{array}$ & 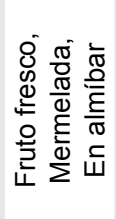 & 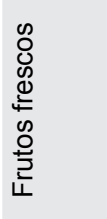 \\
\hline 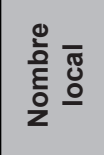 & $\begin{array}{l}\circ \\
\frac{0}{0} \\
\frac{0}{2} \\
\frac{0}{0} \\
\frac{\pi}{4} \\
\frac{\pi}{0}\end{array}$ & 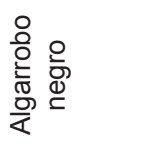 & $\begin{array}{l}\frac{0}{2} \\
\frac{\bar{E}}{\pi} \frac{\pi}{\pi} \\
\frac{\pi}{2} \\
\frac{0}{2}\end{array}$ & 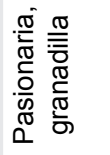 & 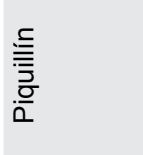 & $\begin{array}{l}\overline{\bar{O}} \\
\stackrel{w}{\underline{w}} \\
\sum\end{array}$ & 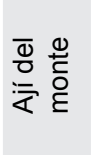 & 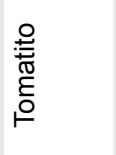 & 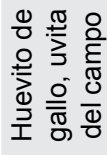 \\
\hline 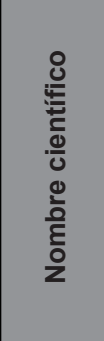 & 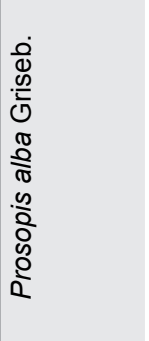 & 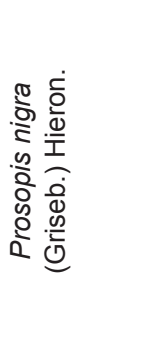 & 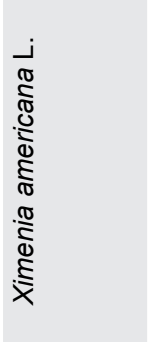 & 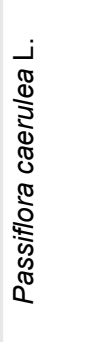 & $\begin{array}{l}\frac{\dot{0}}{0} \\
\frac{0}{\pi} \\
\frac{\pi}{\delta} \\
\delta \\
0\end{array}$ & 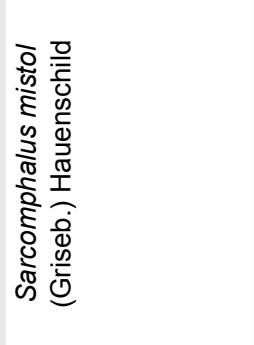 & 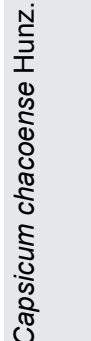 & 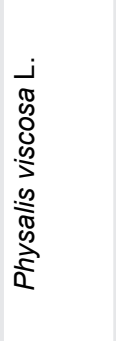 & 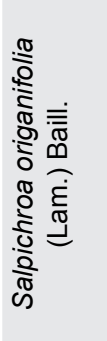 \\
\hline 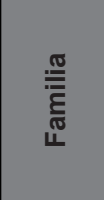 & $\begin{array}{l}\mathbb{1} \\
\mathbb{8} \\
0 \\
\mathbb{0} \\
\mathbb{\pi} \\
\mathbb{1} \\
\mathbb{1}\end{array}$ & $\begin{array}{l}\mathbb{0} \\
\mathbb{\pi} \\
\mathbb{0} \\
\mathbb{\pi} \\
\mathbb{0} \\
\mathbb{1} \\
\stackrel{1}{\leftarrow}\end{array}$ & $\begin{array}{l}\mathbb{D} \\
\mathbb{J} \\
0 \\
\mathbb{J} \\
\mathbb{\pi} \\
0\end{array}$ & 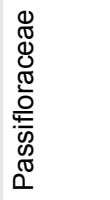 & 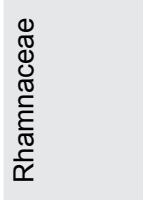 & 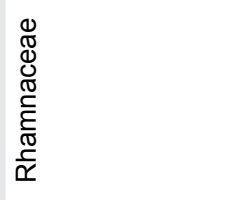 & 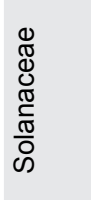 & 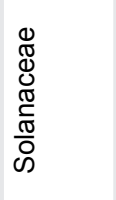 & 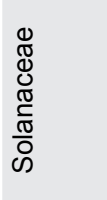 \\
\hline
\end{tabular}




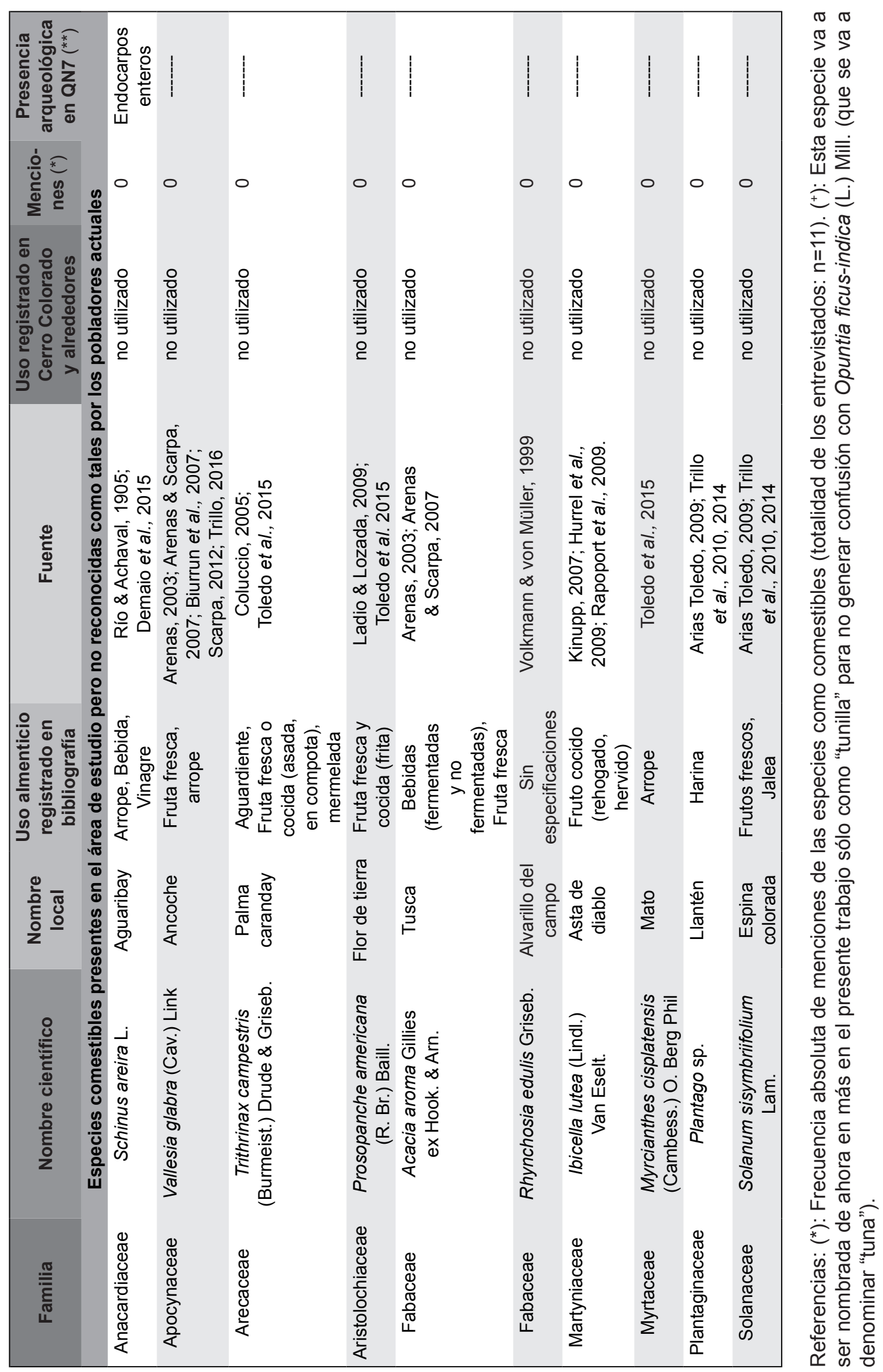




\section{Saur Palmieri et al. - Especies y prácticas de frutos comestibles en Cerro Colorado}

el $65 \%(\mathrm{~N}=13)$ recibe algún tipo de procesado antes de su ingesta, mientras que el $35 \%(\mathrm{~N}=7)$ restante se consume como fruta fresca.

El número total de especies citadas es elevado, con respecto a otros trabajos realizados en la provincia de Córdoba (Arias Toledo, 2008; Trillo et al., 2014), lo que podría interpretarse como un conocimiento más acabado de la oferta de recursos alimenticios del medioambiente circundante. Si bien muchas especies registradas en el presente no conllevan procesamientos, otros autores han mencionado su utilización en la elaboración de productos (Tabla 1); información de interés si se considera que estas prácticas pudieron existir en el pasado cordobés. Asimismo, cuando se analizó el conocimiento de las especies y las prácticas asociadas a su ingesta con la efectiva realización de éstas por parte de los pobladores actuales del área de estudio, se pudo observar que procesan -o han procesado- sólo los frutos de 7 especies de las 13 que conocen que pueden dar origen a alguna preparación comestible. En relación a los productos obtenidos a partir de los frutos de especies silvestres, de los 12 mencionados por los entrevistados, únicamente realizan -o han realizado- 8 de ellos, destacándose la manufactura de arrope (Fig. 2).

La consideración en este trabajo de la Tuna (Opuntia ficus-indica (L.) Mill., Cactaceae), especie no nativa del área de estudio, se debe a su reiterada referencia por parte de los entrevistados, su consideración como recurso muy importante (Tabla 1), y cuyo registro fue similar al realizado previamente por una de las autoras en otras áreas del sector serrano cordobés (Torrico Chalabe \& Trillo, 2015; Ahumada \& Trillo, 2017).

De las especies con frutos comestibles presentes en la zona, 10 no fueron citadas como tal, incluso algunas de ellas no son reconocidas por los pobladores de Cerro Colorado. Estas son aguaribay, ancoche (Vallesia glabra (Cav.) Link, Apocynaceae), caranday (Trithrinax campestris (Burmeist.) Drude

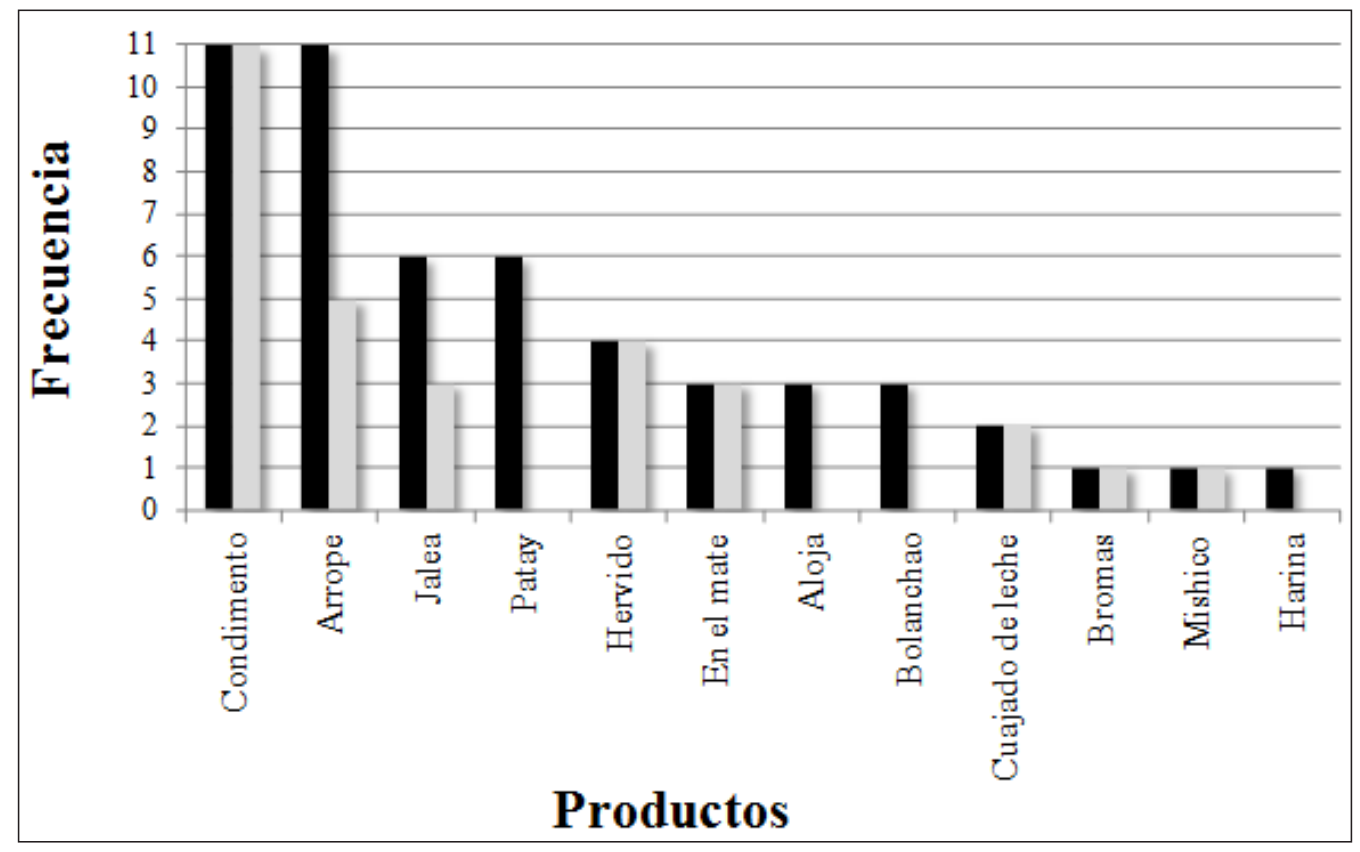

Fig. 2. Histograma de frecuencias absolutas de menciones de productos realizados con frutos de especies vegetales nativas. Referencias: En negro: personas que conocen el producto. En gris: personas que realizan o han realizado alguna vez el producto. 
\& Griseb., Arecaceae), flor de tierra (Prosopanche americana (R. Br.) Baill., Aristolochiaceae), tusca (Acacia aroma Gillies ex Hook. \& Arn., Fabaceae), alvarillo del campo (Rhynchosia edulis Griseb., Fabaceae), asta de diablo (Ibicella lutea (Lindl.) Van Eselt., Martyniaceae), mato, llantén (Plantago sp., Plantaginaceae) y espina colorada (Solanum sisymbriifolium Lam., Solanaceae). Asimismo, existen algunas especies cuyos frutos únicamente fueron mencionados por los entrevistados como colectados ocasionalmente, encontrándose entre ellos tala (Celtis ehrenbergiana (Klotzsch) Liebm., Celtidaceae), tasi (Araujia brachystephana (Griseb.) Fontella \& Goyder, Apocynaceae), pasionaria (Passiflora caerulea L., Passifloraceae), uvita del campo (Salpichroa origanifolia (Lam.) Baill., Solanaceae) y tomatito (Physalis viscosa L., Solanaceae).

\section{Prácticas Precolecta}

De las prácticas previas a la colecta, dos entrevistados mencionaron la tolerancia en ejemplares de chañar y mistol. En ambos casos los árboles en cuestión no habían sido plantados, sino que se desarrollaron espontáneamente cerca de la vivienda y se los toleró en dicho sitio. Datos similares fueron registrados por Trillo (2016) para pobladores de zonas vecinas. Otro manejo registrado en el área de estudio es la "poda", la que se realiza sólo para el piquillín, exactamente en el momento de su colecta para posibilitar su recolección, y no actuando con fines de protección de la planta como lo estipula Casas (2001).

La tolerancia desarrollada por los pobladores de nuestra región de estudio estaría reflejando el interés que existe sobre aquellas especies que poseen múltiples usos, lo cual, siguiendo lo planteado por Scarpa (2012), es un indicio de las intervenciones realizadas en el ambiente doméstico y peri-doméstico para satisfacer sus necesidades básicas.

\section{Colecta}

En cuanto a las técnicas de recolección, se registró que existen dos tipos de colectas la programada y la accidental u ocasional. La colecta programada consiste en la búsqueda intencional y premeditada de frutos, previo conocimiento del tiempo de fructificación y maduración de cada uno de ellos. Estas colectas suelen realizarse cuando existe la intención de procesar la materia prima de alguna manera, i.e. con el fin de obtener un producto derivado. Tanto los niños, por lo general a solicitud de su madre, como los adultos, son los encargados de llevar a cabo esta práctica.

La colecta accidental u ocasional, ocurre cuando se encuentran de forma imprevista los frutos aptos para su consumo, durante recorridos por el campo o cuando los niños están jugando al aire libre, quienes los colectan frecuentemente para la ingesta inmediata como golosina.

Además de las formas de acceder al recurso según la planificación -o no- de la práctica, cada especie vegetal está asociada a una manera particular de colecta. Para mistol, chañar y algarrobo, la misma se realiza en general con los frutos maduros que han caído al suelo o directamente de la planta, muchas veces percutiendo las ramas para que los mismos se desprendan, caigan y así recogerlos. Los árboles de mistol y chañar frecuentados, se localizan cerca de las viviendas, al borde de caminos o en el monte. A veces, se acude a las plantas que se encuentran en las veredas o plazas del pueblo ya que allí las cabras no acceden, lo que favorece que puedan hallarse frutos en mayor cantidad.

Para el caso del piquillín, se extiende una lona, una hoja de nylon o una bolsa por debajo del arbusto y luego se golpean las ramas con un palo o se mueven con las manos para que sus frutos se suelten. Puede recurrirse a "machetear" o "podar" bajo la copa del arbusto, si la vegetación es muy densa, para poder extender la superficie de tela con facilidad. Otra forma mencionada es colectarlos directamente de la planta con la mano.

El albarillo (Ximenia americana L., Olacaceae) puede ser obtenido del suelo o de la planta manualmente. Esta es la única especie citada que, a pesar de ser consumida únicamente como fruta fresca se explicitó la planificación de la colecta además del encuentro ocasional.

La colecta de frutos de cactus suele realizarse con algún instrumento para evitar ser pinchado por las espinas. Entre las herramientas utilizadas se encontró el uso de un palito o ramita seca para las bayas de ulúa (Harrisia pomanensis (F.A.C. Weber ex K. Schum.) Britton \& Rose ssp. pomanensis, Cactaceae) y uvilinche (Cleistocactus baumannii (Lem.) Lem., Cactaceae). Este sirve incluso para rasgar la cáscara y poder acceder a su parte interna. Asimismo, tanto para estas especies como para la 


\section{Saur Palmieri et al. - Especies y prácticas de frutos comestibles en Cerro Colorado}

tunilla (Opuntia sulphurea Gillies ex Salm-Dyck, Cactaceae), se suele utilizar un tenedor como herramienta o un cuchillo (instrumento). Otras personas colectan con la mano o utilizan guantes (herramienta).

Los tipos de colecta arriba mencionados fueron registrados en otras regiones de Argentina (Villafuerte, 1984; Biurrun et al., 2007; Scarpa, 1999, 2012), demostrando que, si bien no constituyen metodologías novedosas para la obtención de los frutos silvestres, existe una práctica extendida y la planificación con fines claros en la procuración, consumo y almacenamiento de los recursos.

\section{Prácticas postcolecta y Consumo}

Luego de la colecta de los frutos nativos comestibles se procede a la ingesta directa, a la elaboración de algún producto o se realizan prácticas concretas destinadas a la conservación del fruto para su utilización diferida.

Se encontraron siete especies que son consumidas únicamente como fruta fresca, con distinto nivel de consenso entre los entrevistados; éstas son uvita del campo (mencionada por el 100\% de los entrevistados), albarillo y ucle (Cereus forbesii Otto ex C.F. Först., Cactaceae) (64\%), tomatito (36\%), cardón (18\%), mishuga (Gymnocalycium schickendantzii (F.A.C. Weber) Britton \& Rose var. schickendantzii, Cactaceae) y quimil (Opuntia quimilo K. Schum., Cactaceae) (las dos últimas con una sola mención, constituyendo el $9 \%$ cada una).

El consumo directo, estrechamente relacionado con la colecta ocasional ya descrita y muchas veces explicado (o justificado) para evitar el "gran trabajo" y tiempo que conllevan las preparaciones, fue previamente referenciada para la provincia de Córdoba por Arias Toledo (2008) quien lo atribuyó a la connotación negativa que el entorno social brinda a la utilización de alimentos silvestres, considerados como "comida de pobre". Sin embargo, en Cerro Colorado y áreas aledañas, en ningún momento se denostó expresamente la utilización de frutos nativos como alimento. Por el contrario, las personas que efectúan estas preparaciones para consumo doméstico, local y, principalmente, para la venta a los turistas, resaltaron que el arrope de chañar y de mistol son muy apreciados y buscados por los compradores.

Con este trabajo, se pudo comprobar que el procedimiento de elaboración de arrope requiere, efectivamente, de una considerable inversión de tiempo (ver más adelante). Esto está muy relacionado con la conservación del conocimiento tradicional y la valoración de las prácticas ancestrales $-\mathrm{O}$ de los productos que con su aplicación se obtienen-. En ese contexto, algunas personas eligen elaborar estos productos regionales y destinarlos a la venta, mientras que otras optan por procurar ingresos a partir de otras actividades. Esto es lo que Cáceres (2014) conceptualiza como elección diferencial de estrategias de reproducción social de pequeños productores campesinos. Lo que significa que, según las oportunidades, necesidades y cuestiones específicas de cada familia y contexto, las personas priorizan una $\mathrm{u}$ otra actividad o combinan diferentes actividades con el objetivo de alcanzar la reproducción de su familia y su modo de vida campesino (Cáceres, 2003, 2014).

\section{Conservación}

Se mencionó que antiguamente los frutos de albarillo se colocaban en agua fresca para retrasar por unas horas la fermentación. Actualmente, la conservación se realiza en un congelador y así poder almacenarlos allí hasta por 6 meses. Con referencia a las vainas de algarrobo y las drupas de chañar y de mistol, ocasionalmente se secan y guardan para el invierno. En particular, el mistol y piquillín se conservan en cajones de madera y cuando se requieren para la ingesta o elaboración de algún producto, se rehidratan en agua caliente. La prevención de infestaciones de insectos u hongos en esta etapa solo fue referenciada por una de las autoras para la misma área de estudio, en cuya entrevista se mencionó el agregado de paico (Dysphania ambrosioides (L.) Mosyakin et Clemants, Chenopodiaceae) en las cajas o costales de arpillera de nylon junto al algarrobo (López \& Capparelli, 2014). No obstante, las entrevistas realizadas para el presente trabajo no dieron cuenta de ninguna práctica similar.

Una forma peculiar de conservación de mistol es la de elaboración de una pasta con el fruto, el cual se coloca en un cajón sin retirar las semillas y se aplasta. A medida que este preparado se va secando, "se azucara", "concentra el dulzor de la fruta" y se vuelve compacto. En el momento de utilizarse, se corta con un cuchillo para obtener una porción de dicha masa endurecida. Este método de almacenamiento fue registrado por Arenas (2003) 
entre los aborígenes del Chaco, quienes compactan las vainas secas de Prosopis alegando que de esta manera se evita el ataque de insectos. En Cerro Colorado, solo se lo mencionó como práctica de conservación del fruto fuera de estación.

Finalmente, hay referencias respecto a la producción de arropes y jaleas o mermeladas (ver más adelante) que, si bien mayormente no son consideradas como forma de almacenamiento, su consumo es diferido y permite que éste se efectúe fuera de la época de fructificación.

\section{Molienda}

El ají del monte (Capsicum chacoense Hunz., Solanaceae) fue el recurso mencionado cuando se habló de molienda, ya que es destinado a condimentar embutidos y salsas. Además, se destacó su uso para bromas debido a que es muy picante; se suele colocar en alimentos en gran cantidad para sorprender a algún desprevenido. También, algunos informantes mencionaron el molido de las vainas de algarroba en mortero manual durante la elaboración de arrope (ver más adelante) como así también para obtener harina. Un caso particular fue registrado por López \& Capparelli (2014) en la región de estudio, cuya entrevistada preparó harina no refinada a partir de las vainas enteras utilizando una máquina de moler maíz, método implementado para acelerar el tiempo de procesamiento y minimizar el esfuerzo.

\section{Arropes y jaleas}

En la región de Cerro Colorado y alrededores se conocen los arropes de chañar, mistol, algarroba, piquillín, tala, molle, tunilla, tuna, ulúa y uluvinche. Sin embargo, los entrevistados han realizado alguna vez, o realizan periódicamente este producto, sólo a partir de frutos chañar, mistol, piquillín, tunilla y tuna.

El "arrope" posee un origen dudoso que puede remitirse a la elaboración prehispánica de jugos cocidos de frutas en el actual territorio peruano o los jarabes medicinales (concentrados de frutas recocidas) que los árabes introdujeron en España (Scarpa, 1999). En la región estudiada la receta de este preparado resultó, entre las personas entrevistadas, relativamente similar para las distintas especies. Su elaboración consiste en el hervido de los frutos hasta ablandarlos, seguido del amasado, el cual se denomina "chaguado". En este paso, los frutos se rompen con las manos. En esta tarea, si la pasta está muy seca, puede agregarse agua. Después, ese preparado se pasa por un colador de modo de separar las semillas y recoger el líquido resultante. En general, el amasado y el colado se realizan simultáneamente, es decir que los frutos se aprietan a mano sobre el colador y a medida que escurre el líquido, va pasando al recipiente colocado debajo. Posteriormente se filtra con una tela de malla fina. El líquido obtenido de estos dos filtrados se hace hervir en una olla hasta que se torna viscoso. La cocción generalmente se realiza en fogones a leña. El fuego es de intensidad intermedia, ya que si es muy fuerte el producto se "arrebata", es decir no se logra ni la consistencia ni el sabor deseados. El arrope se retira del fuego cuando se coloca un poco en una cuchara de madera y al verterlo "la hebra no se corta" o "cae en forma de tres hilos". A este preparado de consistencia líquida, también suele llamarse "jarabe". En general, partiendo de $15 \mathrm{~L}$ de la mezcla resultante de frutos y agua se obtiene 1,5 L de arrope a través de 6 horas y media de trabajo individual.

La "jalea" (que también puede llamarse "mermelada") se obtiene con los mismos pasos que la preparación antes descripta excepto que sólo se cuela una vez. De esta forma, y luego del hervido final, se obtiene un producto de consistencia untable. En Cerro Colorado se conocen jaleas de chañar, mistol, algarroba blanca, algarroba negra y de tuna. Sin embargo, sólo aquellas elaboradas con ambos algarrobos son elaboradas, o lo han sido alguna vez, por los entrevistados en este trabajo, en cuyo preparado suele mencionarse la molienda de las vainas después del hervido y antes del chaguado. Todas las mermeladas registradas se preparan a partir de los frutos enteros, a excepción de la de tuna que se elabora con el residuo del colado del arrope.

Para la elaboración del arrope de tuna, muchas veces mezclado con tunilla, se emplea un instrumento fabricado con ramas (no se aludió a ninguna especie leñosa en particular) denominada "noque". Consta de una especie de mesa formada por palos de madera ubicados horizontalmente y separados a poca distancia. Esta estructura es sostenida por cuatro patas del mismo material. La parte horizontal constituye el apoyo donde se coloca una bolsa de tela con los frutos hervidos y así se produce el primer filtrado propio de la 


\section{Saur Palmieri et al. - Especies y prácticas de frutos comestibles en Cerro Colorado}

receta. El amasado se realiza allí para contribuir al escurrido del líquido. No obstante, si la preparación no se ha enfriado, impidiendo la manipulación con las manos por encontrarse a muy alta temperatura, se coloca una piedra pesada arriba de la bolsa para que vaya drenando el líquido mientras se espera que se puedan amasar. Debajo de la mesa, se coloca una tela o bolsa de tela, colgada de los cuatro palos que sirven de apoyos, y así proceder directamente al segundo filtrado del arrope. El líquido que ha pasado por los dos filtros cae en un recipiente ubicado en el suelo, que luego es hervido para obtener el producto final. Los entrevistados mencionaron que en el pasado en cada hogar existía un noque.

Para los frutos de piquillín, inmediatamente después de la colecta, son retiradas a mano las espinas que hayan caído en la lona de colecta y posteriormente se vierte el contenido de ésta en un recipiente con agua para quitar, también a mano, las hojas que flotan. A pesar de lo ya puntualizado, el "arrope" de piquillín se realiza con un solo filtrado y a pesar de ello no se denomina "jalea". Esto probablemente se debe a que con una sola pasada por el colador se obtiene un líquido con escasas impurezas que al cocinarlo mantiene su consistencia líquida y no se torna denso como la "jalea" típica.

Los residuos de estas preparaciones (como los frutos descartados y lo que queda luego del colado y el filtrado) se arrojan a los animales (cerdos, caballos) en el caso de que el entrevistado efectúe su crianza, o en algún sitio descampado próximo al lugar de producción. No se ha mencionado el vertido al fogón, a modo de combustible, de ninguno de los residuos.

Ante lo expuesto en relación a la elaboración de arrope de chañar, piquillín y algarroba, se encontró que el procedimiento mencionado en el área de estudio coincide con la bibliografía preexistente (Di Lullo, 1935; Figueroa \& Dantas, 2006; Capparelli, 2007). De esta manera, se acuerda parcialmente con Scarpa (1999) que plantea la "homogeneidad" en la cadena de elaboración de dicho producto, a pesar de la gran cantidad de especies utilizadas y el extenso territorio donde este se realiza. En efecto, a pesar de que los pasos generales son comunes, hemos observado algunas variaciones. Mientras que Scarpa (1999) alude a la molienda en morteros previa al primer hervido de los frutos como fase típica de esta técnica, en el presente trabajo registramos en ocasiones el preparado sin previa molienda, como así también el simple fragmentado de los frutos como registraron López \& Capparelli (2014).

Otras prácticas (alternativas en formas de almacenamiento, conservación y consumo)

En Cerro Colorado se conoce la existencia, aunque no es realizado por ninguno de los entrevistados, del bolanchao, dulce típico del norte argentino (Di Lullo, 1935; Biurrun et al., 2007; Rapoport et al., 2009; Rosalía \& Rionda, 2015), también conocida como mishico, mishchico o pichico. Es una golosina elaborada a partir de mistol, la cual se comienza la preparación moliendo el fruto y luego haciendo pequeñas esferas con azúcar (en la que la semilla queda en el centro) y uniéndolas con harina de algarroba. Esta preparación suele conservarse en cajones, reservando su consumo para el invierno.

El hervor de los frutos en distintos medios líquidos fue referido a productos con características medicinales o como postre. Así, se mencionó que el chañar puede consumirse para calmar la tos. Mientras que el mistol y el piquillín, hervidos en agua o en leche, se consumen en forma de postre. A pesar de que se conoce la existencia regional de patay y aloja, productos reconocidos como tradicionales en la bibliografía (Río \& Achával, 1905; Di Lullo, 1935), no se registró su actual elaboración en el área. En cambio, se ha referido que el patay puede adquirirse en Santiago del Estero.

Los frutos de molle se emplean para endulzar o saborizar al mate, siendo ésta la única utilidad actual de la especie como comestible en Cerro Colorado y alrededores. Con respecto al tasi, se acostumbra a hervir el folículo de esta planta e incorporarlo a las sopas. Además, se mencionó que su látex puede utilizarse para cuajar la leche. El ají del monte se utiliza para condimentar salsas y embutidos de cerdo. Se aludió que el fruto de pasionaria puede ser aprovechado para elaborar mermelada (mediante el hervido con agregado de azúcar).

De forma similar a lo reportado por Biurrun et al. (2007) en La Rioja, las personas de Cerro Colorado comentan que al presente han disminuido el tipo y cantidad de preparaciones con frutos silvestres. Por ejemplo, en este trabajo, varios entrevistados hicieron alusión a que sus madres 
elaboraban productos que ellos nunca prepararon, o que en el pasado habían probado algún producto que ellos nunca elaboraron. Diversos autores (Biurrun et al., 2007; Arias Toledo, 2008; Crúz et al., 2013; do Nascimento et al., 2016) atribuyen este hecho, por un lado, a la infraestructura vial que facilita el acceso a alimentos publicitados y consumidos en las ciudades; por otro, el hecho de considerar al consumo de alimentos silvestres como un signo de pobreza y, finalmente, la menor transmisión de los conocimientos a los jóvenes debido a su desinterés o a que emigran a los grandes centros urbanos. En Cerro Colorado, los mismos procesos socioculturales mencionados podrían estar afectando la utilización de frutos de plantas nativas comestibles. En este sentido hay evidencias sobre la gran emigración rural de jóvenes en el norte cordobés y el reemplazo de la actividad relacionada a la producción artesanal -las que refuerzan el mantenimiento del conocimiento botánico localpor tareas inherentes al turismo (Silvetti \& Cáceres, 1998).

Los pobladores entrevistados en el área de estudio no conocen todas las plantas de frutos comestibles existentes en el lugar y, además no utilizan todas las plantas que reconocen como alimenticias. Este hecho, también reportado en La Rioja por Biurrun et al. (2007) y en la Patagonia en comunidades Mapuches por Ladio (2001), da cuenta de que el saber está en peligro ya que el uso efectivo de los recursos es lo que asegura que el conocimiento sobre los mismos no se pierda (Trillo et al., 2007). Dado que la región fitogeográfica del Chaco es un "reservorio importante de material nutricio", como plantean Arenas \& Martínez (2012), y que la provincia de Córdoba se enfrenta al avance de la frontera agropecuaria que produce pérdida de biodiversidad y desaparición de campesinos (Cáceres et al., 2010), la utilización efectiva de los bienes naturales es un aspecto clave en su conservación, un vínculo necesario con el conocimiento ecológico tradicional (Trillo et al., 2007).

\section{Implicancias para el análisis e interpretación paleoetnobotánica}

En el marco de estudios paleoetnobotánicos que vienen realizándose en el país y que tienen como objetivo la interpretación del rol desempeñado por los vegetales en sus respectivos contextos arqueológicos (Capparelli et al., 2015), así como los avances logrados en los estudios de macro y microrrestos botánicos recuperados en diversos sitios arqueológicos en la provincia de Córdoba (López, 2017), este trabajo pretende exponer la riqueza de recursos que actualmente se registran como alimenticios y que pudieron constituir parte de la dieta de los pueblos asentados en el sector serrano cordobés. De esta manera, una base de datos etnobotánica con información detallada en referencia a las prácticas precolecta, colecta, postcolecta, consumo y descarte de los recursos silvestres chaqueños, puede servir para la interpretación de dichas esferas de actividades durante el pasado prehispánico (400-1550 d.C.) y en las primeras décadas del período colonial (1550-1650 d.C.).

Al evaluar el registro macrobotánico de especies nativas que fueron recuperadas en el sitio arqueológico QN7 (López, 2017; Recalde \& López, 2017) (Tabla 1), se observa que la mayoría de los taxones identificados tiene su correlato actual. Mistol, molle, chañar, algarrobo y piquillín fueron reconocidas como frutos comestibles marcando así la continuidad a través del tiempo desde momentos prehispánicos. La amplia riqueza vegetal comestible actualmente registrada en Cerro Colorado y alrededores no excluye la posibilidad de la inclusión de un número mayor de recursos en la dieta prehispánica más allá de aquellos recuperados hasta el momento en QN7. En este sentido, se debe tener en cuenta que el material botánico arqueológico representa sólo una pequeña porción del rango de plantas consumidas en el pasado. Además, hay más probabilidades de encontrarse vegetales utilizados cotidianamente y relacionados con prácticas que involucran el fuego (Stevens, 2003), sumado a la respuesta diferencial de cada órgano vegetal a la exposición al calor (Wright, 2003). Por tal, encontrar frutos que han sido consumidos en el pasado de manera directa (ingesta en fresco) y/o colectados ocasionalmente dependerá, si no han sido arrojados al fuego como material combustible, de los análisis de microrrestos (fitolitos, granos de almidón y tejidos celulares) presentes en tártaro dental de individuos provenientes de entierros localizados en el área de estudio.

Con respecto a las prácticas desarrolladas con los frutos nativos, hay ciertas características en las que podemos inferir una cierta profundidad histórica, tanto prehispánica como colonial. Las prácticas de precolecta, colecta y consumo son no visibles desde 


\section{Saur Palmieri et al. - Especies y prácticas de frutos comestibles en Cerro Colorado}

el punto de vista arqueológico si nos referimos exclusivamente a los recursos silvestres y a través de macrorrestos. Aún cuando, por ejemplo, la "poda" podría ser hipotetizada a través del registro antracológico, no habría manera de determinar si la especie identificada proviene de leña muerta y seca o si fue extraída a partir de la poda.

Las actividades que se engloban en la esfera de la postcolecta pueden ser identificadas a través de los macrorrestos arqueológicos botánicos (Capparelli \& Lema, 2010). Casos concretos de estudio paleoetnobotánicos desarrollados por Capparelli (2008; Capparelli \& Lema, 2011), López et al. (2011), Petrucci \& Lema (2016), entre otros, han demostrado que los caracteres adquiridos por los frutos tras su procesamiento previo a la ingesta, dejan huellas microanatómicas que persisten más allá de los procesos tafonómicos en los cuales se ven involucrados los restos arqueológicos tras su depositación final en un sitio. En el caso aquí considerado, podemos discriminar principalmente el almacenamiento, la molienda y el hervido de los frutos, más allá de los productos finales, como prácticas posiblemente desarrolladas por los pobladores prehispánicos cordobeses. Las primeras aproximaciones a dichas actividades fueron obtenidas tras el análisis de endocarpos de algarrobo del sitio QN7, donde las características que los macrorrestos pueden asociarse a la molienda de las vainas para la obtención de harina no refinada (López \& Capparelli, 2014). De igual manera, restos de mistol del mismo sitio fueron interpretados como almacenados a largo plazo (López et al., 2015).

Los datos etnobotánicos aquí presentado permiten considerar la existencia de prácticas que, si bien pueden conocerse a través de la bibliografía, es importante determinar que se desarrollan, y pudieron desarrollarse en el pasado, en cercanías del sitio arqueológico (Margaritis \& Jones, 2006). Es el caso del almacenamiento por aplastamiento, ya descrito por Arenas (2003) para el Noreste de Argentina, y que observamos que también se desarrolla en nuestra área de estudio. Corresponderá a futuro indagar sobre las características que adquieren los frutos tras la prolongada conservación con esta metodología y sus posibles huellas. Cabe asimismo observar que los recursos recuperados de restos arqueológicos (Tabla 1) pudieron ser consumidos de maneras diferentes a las registradas actualmente. Es el caso del molle, cuyos frutos presentan una frecuencia relativa a nivel arqueológico del $58 \%$ en la asociación carpológica del sitio QN7 (López, 2017), muchos de ellos indicando su posible almacenamiento. Las personas entrevistadas remarcaron sólo utilizarlos para endulzar y/o saborizar el mate, pero en el pasado debió responder como un recurso de mayor versatilidad que el indicado.

\section{Conclusiones}

Los datos expuestos en este trabajo permiten, en primer lugar, observar la riqueza de especies chaqueñas nativas presentes en el norte cordobés y cuyos frutos son comestibles, sea de modo directo (fruta fresca) o mediante procesamiento (fruta cocida). En segundo lugar, describir las prácticas de precolecta, colecta, postcolecta, consumo y descarte que se realizan con cada uno de los frutos procesados e ingeridos, permitiendo acceder a detalles necesarios para abordar posteriormente los trabajos de índole paleoetnobotánicos. Finalmente, aproximar los datos actuales a los arqueológicos, distinguiendo aquellos recursos cuya continuidad a través del tiempo pueden ser fácilmente abordadas, de aquellos otros que parecen ser parte de la discontinuidad en su manipulación. El CET juega su rol en este aspecto, donde si bien la profundidad temporal no es condicionante, su dinamismo puede llevar a cambios, transformaciones y/o pérdidas de las prácticas relacionadas a los recursos nativos del ambiente circundante, y a través del registro arqueológico botánico puede reflejar este dinamismo.

\section{Agradecimientos}

A todas las personas entrevistadas que nos permitieron realizar este trabajo y especialmente a Ángela. A los dos revisores anónimos por sus útiles sugerencias.

El presente trabajo se realizó en el marco de una "Beca Estímulo a las Vocaciones Científicas" del CIN y con la financiación del proyecto "Percepción, manejo y uso de unidades de paisaje en zonas rurales de Córdoba, transformaciones en el tiempo" (Res. 313/16, SECyT-UNC). 


\section{Biblografía}

AGUILERA, R. M., A. DURAND-SMITH, E. M. RODRÍGUEZ \& M. ROMERO MENDOZA. 2003.

Veinticinco años de investigación cualitativa en salud mental y adicciones con poblaciones ocultas. Primera parte. Salud Mental 26: 76-83.

AHUMADA, M. L. \& C. TRILLO. 2017. Diversidad de especies naturalizadas del género Opuntia (Cactaceae) utilizadas por los pobladores del norte de Córdoba (Argentina). Bol. Soc. Argent. Bot. 52: 193-208.

ARENAS, P. A. 1995. Encuesta etnobotánica: aplicada a indígenas del Gran Chaco. En: BRAUNSTEIN, J. (Comp.), Hacia una nueva Carta Étnica del Gran Chaco 6, pp. 161-178. Centro del Hombre Antiguo Chaqueño, Las Lomitas.

ARENAS, P. A. 2003. Etnografia y alimentación entre los Toba-Ñachilamole\#ek y Wichi-Lhuku'tas del Chaco Central (Argentina). Edición del autor, Buenos Aires.

ARENAS, P. \& G. J. MARTÍNEZ. 2012. Estudio etnobotánico en regiones áridas y semiáridas de Argentina y zonas limítrofes. Experiencias y reflexiones metodológicas de un grupo de investigación. En: ARENAS, P. (Ed.), Etnobotánica en zonas áridas y semiáridas del Cono Sur de Sudamérica, pp. 11-43. CONICET, Buenos Aires.

ARENAS, P. \& G. F. SCARPA. 2007. Edible wild plants of the chorote Indians, Gran Chaco, Argentina. Bot $J$ Linn Soc 153: 73-85.

ARIAS TOLEDO, B. 2008. Disponibilidad y uso de las plantas silvestres alimenticias y medicinales en las Sierras de Córdoba: su asociación con factores fitogeográficos y culturales. Tesis Doctoral, FCEFyNUNC.

ARIAS TOLEDO, B. 2009. Diversidad de usos, prácticas de recolección y diferencias según género y edad en el uso de plantas medicinales en Córdoba, Argentina. BLACPMA 8: 389-401.

ARIAS TOLEDO, B., S. COLANTONIO \& L. GALETTO. 2007. Knowledge and use of edible and medicinal plants in two populations from the Chaco forest, Córdoba province, Argentina. Journal of Ethnobiology 27: 218-232.

BERKES, F. 1999. Sacred ecology. 3rd ed. Routledge, New York.

BERKES, F., J. COLDING \& C. FOLKE. 2000. Rediscovery of traditional ecological knowledge as adaptive management. Ecol Appl 10: 1251-1262.

BERNARD H. R. 1995. Research Methods in Anthropology Qualitative and Quantitative Approaches. 2nd ed. Altamira, UEA.

BIURRUN, E., L. GALETTO, A. M. ANTON \& F. BIURRUN. 2007. Plantas silvestres comestibles utilizadas en poblaciones rurales de la Provincia de La Rioja (Argentina). Kurtziana 33: 121-140.
BURKART, R., N. O. BÁRBARO, R. O. SÁNCHEZ \& D. A. GÓMEZ. 1999. Eco-regiones de la Argentina. SRNyDS - APN, Buenos Aires.

BUXÓ, R. 1997. Arqueología de las plantas. La explotación económica de las semillas y los frutos en el marco mediterráneo de la Península Ibérica. Crítica, Barcelona.

CABIDO, M. \& M. ZAK. 1999. Vegetación del Norte de Córdoba. Secret. Agric., Ganad y Rec. Renov. Prov. Cba, Córdoba.

CABRERA, A. L. 1976. Regiones fitogeográficas argentinas. Enciclopedia Argentina de Agricultura $y$ Jardinería. 2nd ed. ACME, Buenos Aires.

CÁCERES, D. M. 2003. El Campesinado Contemporáneo. En: THORNTON, R. \& G. CIMADEVILLA (Eds.), La Extensión Rural en Debate. Concepciones, Retrospectivas, Cambios y Estrategias para el MERCOSUR. INTA, Buenos Aires.

CÁCERES, D. M. 2014. Amenazas y desafios que enfrenta el campesinado en Argentina. ¿Descampesinización o Persistencia? En: CRAVIOTTI, C. (Ed.), Agricultura Familiar en Latinoamérica. Continuidades, Transformaciones y Controversias, pp. 205-232. Ciccus, Buenos Aires.

CÁCERES, D. M., G. SOTO, G. FERRER, F. SILVETTI \& C. BISIO. 2010. La expansión de la agricultura industrial en Argentina Central. Su impacto en las estrategias campesinas. Cuad Desarro Rural 7: 89-117.

CAPPARELLI, A. 2007. Los productos alimenticios derivados de Prosopis chilensis (Mol.) Stuntz y $P$. flexuosa DC., Fabaceae, en la vida cotidiana de los habitantes del NOA y su paralelismo con el algarrobo europeo. Kurtziana, 33: 1-19.

CAPPARELLI, A. \& V. LEMA. 2010. Prácticas poscolecta/ post-aprovisionamiento de recursos vegetales: una perspectiva paleoetnobotánica integradora aplicada a casos de Argentina. En: BÁRCENA, J. R. \& H. CHIAVAZZA (Eds.), Arqueología Argentina en el Bicentenario de la Revolución de Mayo 3, pp. 1171-1176. $17^{\circ}$ Congreso Nacional de Arqueología Argentina, Mendoza.

CAPPARELLI, A. \& V. LEMA. 2011. Recognition of post-harvest processing of algarrobo (Prosopis spp.) as food from two sites of Northwestern Argentina: an ethnobotanical and experimental approach for desiccated macroremains. Archaeol Anthropol Sci 3: 71-92.

CAPPARELli, A., V. LEMA, M. L. LÓPEZ, D. ANDREONI, M. L. CIAMPAGNA, A. MARTÍNEZ, N. PETRUCCI, D. GOBBO \& M. L. POCHETTINO. 2015. El estudio de la dinámica de interacciones humanos-plantas en Argentina: Historia de la construcción de un abordaje interdisciplinar desde el Museo de la Plata (FCNyM-UNLP). Comechingonia 19: 19-53. 


\section{Saur Palmieri et al. - Especies y prácticas de frutos comestibles en Cerro Colorado}

CAPITANELLI, J. 1979. Geomorfología. En: VAZQUEZ, J., R. MIATELLO \& M. ROQUE (Eds.), Geografía Física de la Provincia de Córdoba, pp. 213-296. Editorial Boldt, Buenos Aires.

CASAS, A. 2001. Silvicultura y domesticación de plantas en Mesoamérica. En: RENDÓN AGUILAR, B., S. REBOLLAR DOMÍNGUEZ, J. CABALLERO NIETO \& M. A. MARTÍNEZ ALFARO (Eds.), Plantas, Cultura y Sociedad, pp. 123-157. Universidad Autónoma Metropolitana- Iztapalapa, México.

CASAS, A., F. PARRA, F., J. BLANCAS, S. RANGELLANDA, M. VALLEJO, C. J. FIGUEREDO \& A. I. MORENO-CALLES. 2016. Origen de la domesticación y la agricultura: cómo y por qué. En: CASAS, A., J. TORRES-GUEVARA \& F. PARRA (Eds.), Domesticación en el continente americano 1. Manejo de biodiversidad y evolución dirigida por las culturas del Nuevo Mundo, pp. 189-224. UNAMUNALM, México.

COLUCCIO, F. 2005. Diccionario folklórico de la flora y la fauna de América. Ediciones del Sol, Buenos Aires.

CRÚZ, M. P., N. PERONI \& U. P. ALBUQUERQUE. 2013. Knowledge, use and management of native wild edible plants from a seasonal dry forest $(\mathrm{Ne}$, Brazil). J Ethnobiol Ethnomed 9: 1-10.

DEMAIO, P., U. O. KARLIN \& M. MEDINA. 2015. Árboles nativos de Argentina: Centro y Cuyo. Ecoval, Córdoba.

DI LULlO, O. 1935. La alimentación popular de Santiago del Estero. Franco Rossi, Santiago del Estero.

DO NASCIMENTO, V. T., L. DE OLIVEIRA CAMPOS \& U. P. ALBUQUERQUE. 2016. Food Plants. En: ALBUQUERQUE, U. P., U. ROMEU \& N. ALVES (Eds.), Introduction to Ethnobiology, pp. 137-142. Springer, Switzerland.

FERREIRA JÚNIOR, W. S., A. L. B. NASCIMENTO, M. A. RAMOS, P. M. DE MEDEIROS, G. T. SOLDATI, F. R. SANTORO, V. REYES-GARCÍA \& U. P. ALBUQUERQUE. 2015. Resilience and Adaptation in Social-Ecological Systems. En: ALBUQUERQUE, U. P., P. M. DE MEDEIROS \& A. CASAS (Eds.), Evolutionary Ethnobiology, pp. 105-119. Springer, Switzerland.

FIGUEROA, G. G. \& M. DANTAS. 2006. Recolección, procesamiento y consumo de frutos silvestres en el noroeste semiárido argentino. Casos actuales con implicancias arqueológicas. La Zaranda de Ideas 2: $35-50$.

FORD, R. I. 1978. Ethnobotany: Historical Diversity and Synthesis. En: FORD, R. I. (Ed.), The nature and status of Ethnobotany, pp. 33-49. Ann Arbor, Michigan.
GIORGIS, M. A., A. M. CINGOLANI, F. CHIARINI, J. CHIAPELLA, G. BARBOZA, L. ARIZA ESPINAR, R. MORERO, D. E. GURVICH, P. A. TECCO, R. SUBILS \& M. CABIDO. 2011. Composición florística del Bosque Chaqueño Serrano en la provincia de Córdoba, Argentina. Kurtziana 36: 9-43.

GIOVANNETTI, M., A. CAPPARELli \& M. L. POCHETTINO. 2008. La arqueobotánica en Sudamérica ¿hacia un equilibrio de enfoques? Discusión en torno a las categorías clasificatorias y la práctica arqueobotánica y paleoetnobotánica. En: ARCHILA, S., M. GIOVANNETTI \& V. LEMA (Comps.), Arqueobotánica y Teoría Arqueológica. Discusiones desde Sudamérica, pp. 17-34. UNIANDES, Bogotá.

GUBER, R. 1991. El Salvaje Metropolitano. Legasa, Buenos Aires.

HASTORF, C. A. 1999. Recent Research in Paleoethnobotany. J Archaeol Res 7: 55-103.

HILLMAN, G. C. 1973. Crop husbandry and food production: modern basis for the interpretation of plant remains. Anatolian Studies 23: 241-244.

HILLMAN, G. C. 1984. Interpretation of archaeological plant remains: The application of ethnographic models from Turkey. En: VAN ZEIST, W. \& W. A. CASPARY (Eds.), Plants and Ancient Man. Studies in palaeoethnobotany, pp. 1-41. A. Balkema, Rotterdam.

HURRELL, J. A. \& U. P. DE ALBUQUERQUE. 2012. Is Ethnobotany an Ecological Science? Steps towards a complex Ethnobotany. Ethnobio Conserv, 1: 4.

HURRELL, J. A., E. A. ULIBARRI, G. DELUCCHI \& M. L. POCHETTINO. 2009. Biota Rioplatense XIV. Hortalizas. Verduras y legumbres. L.O.L.A., Buenos Aires.

INDEC. 2010. Censo Nacional de Población, Hogares y Viviendas. Argentina. Disponible en: www.indec. gov.ar [Acceso: abril 2016].

INSTITUTO DE BOTÁNICA DARWINION. 2017. Catálogo de las Plantas Vasculares del Cono Sur. Disponible en: www.darwin.edu.ar [Acceso: agosto de 2017].

KINUPP, V. 2007. Plantas alimenticias nãoconvencionais da região metropolitana de Porto Alegre, RS. Tesis Doctoral. Faculdade de Agronomia-UFRGS.

LADIO, A. H. 2001. The maintenance of wild edible plant gathering in a Mapuche community of Patagonia. Econ Bot, 55: 243-254.

LADIO, A. H. \& M. LOZADA. 2009. Human ecology, ethnobotany and traditional practices in rural populations inhabiting the Monte region: resilience and ecological knowledge. J Arid Environ 73: 222227. 
LEMA, V. 2009. Domesticación Vegetal y Grados de Dependencia Ser Humano-Planta en el Desarrollo Cultural Prehispánico del Noroeste Argentino. Tesis Doctoral, FCNyM-UNLP.

LEMA, V. 2011. Lo micro en lo macro: el tratamiento microscópico de macrorestos vegetales para la identificación de prácticas y modos de relación con el entorno vegetal en el estudio arqueológico de la domesticación vegetal. Arqueología 17: 57-79.

LÓPEZ, M. L. 2015. La cocina como medio para la reproducción social de los grupos prehispánicos de las sierras de Córdoba. En: SALAZAR, J. (Ed.), Condiciones de Posibilidad de la Reproducción Social en Sociedades Prehispánicas y Coloniales Tempranas en las Sierras Pampeana (República Argentina), pp. 177-212. Centro de Estudios Históricos Prof. Carlos S. A. Segreti, Córdoba.

LÓPEZ, M. L. 2017. Archaeobotany in Central Argentina. Macro and micro remains at several archaeological sites from early Late Holocene to early Colonial Times (3000-250 B.P.). Veg Hist Archaeobot. DOI 10.1007/s00334-017-0627-x

LÓPEZ, M. L. \& A. CAPPARELLI. 2014. Algarrobo pods (Prosopis sp., Fabaceae) in the Central and Northwestern Argentina. Food-traditional products and technological innovations involved in their manufacture. En: HERRERA MOLINA, F, F. TARIFA GARCÍA \& E. HERNÁNDEZ BERMEJO (Eds.), Etnobotánica 2.14. La riqueza de un legado. IV Congreso Internacional de Etnobotánica, pp. 203. Córdoba, España.

LÓPEZ, M. L., A. CAPPARELLI \& A. NIELSEN. 2011. Traditional post-harvest processing to make quinoa grains (Chenopodium quinoa var. quinoa) apt for consumption in Northern Lipez (Potosí, Bolivia): ethnoarchaeological and archaeobotanical analyses. J Archaeol Sci 3: 49-70.

LÓPEZ, M. L. \& M. A. RECALDE. 2016. The first quinoa (Chenopodium quinoa Willd) macrobotanical remains at Sierras del Norte (Central Argentina) and their implications in pre-Hispanic subsistence practices. J Archaeol Sci 8: 426-433.

LÓPEZ, M., C. TRILLO \& M. RECALDE. 2015. El consumo de mistol (Ziziphus mistol) en el sitio prehispánico Quebrada Norte 7 (Cerro Colorado, Córdoba). Inferencias de prácticas culinarias a partir de datos etnobotánicos. Libro de Resúmenes y Cronograma de las VI Jornadas Arqueológicas Cuyanas (p. 38). San Rafael, Mendoza.

MARGARITIS, E. \& M. JONES. 2006. Beyond cereals: crop processing and Vitis vinifera L. Ethnography, experiment and charred grape remains from Hellenistic Greece. J Archaeol Sci 33: 784-805.

MARTIN, G. J. 1995. Etnobotánica. Manual de métodos. Royal Botanic Garden, Londres.
MAUSS, M. 2006. Manual de etnografía. Fondo de cultura económica. México.

PADUA, J. 1994. Técnicas de investigación aplicadas a las ciencias sociales. Fondo de Cultura Económica Chile, Santiago de Chile.

PAVÁN, F. 2012. Diagnóstico ambiental y propuestas de manejo sustentable. Paraje El Desmonte, Reserva Cultural-Natural Cerro Colorado. Tesina de Grado. FCEFyN-UNC.

PEARSALL, D. M. 2016. Paleoethnobotany: A Handbook of Procedures. 3rd ed. Routledge, New York.

PETRUCCI, N. \& V. S. LEMA. 2016. Primeras aproximaciones a la identificación de técnicas de procesamiento en carporrestos de Zea mays L.: detección de granos hervidos en restos arqueobotánicos secos y carbonizados. Intersecc antropol 17: 291-302.

POCHETTINO, M. L. \& V. S. LEMA. 2008. La variable tiempo en la caracterización del conocimiento botánico tradicional. Darwiniana 46: 227-239.

POLITIS, G. 2004. Tendencias de la etnoarqueología en América Latina. En: POLITIS, G. \& R. PERETTI (Eds.), Teoría Arqueológica en América del Sur, pp. 85-117. Serie Teórica INCUAPA, Olavarría.

RAPOPORT, E. H., A. MARZOCCA \& B. S. DRAUSAL. 2009. Malezas comestibles del Cono Sur y otras partes del planeta. INTA, Buenos Aires.

RECALDE, A. 2015. Representaciones en contexto. Características del paisaje rupestre de Cerro Colorado (Sierras del norte, Córdoba, Argentina). Relaciones 40: 523-548.

RECALDE, A. \& L. LÓPEZ. 2017. Las sociedades prehispánicas tardías en la región septentrional del centro de Argentina (Sierras del Norte, Córdoba). Avances a su conocimiento desde los recursos vegetales. Chungara. En prensa.

RÍO, M. \& L. ACHÁVAL. 1905. Geografía de la Provincia de Córdoba. Compañía sud-americana de Billetes de Banco, Buenos Aires.

ROSALÍA, P. \& P. RIONDA. 2015. Relatos del viento. Recopilación de tradiciones orales del norte cordobés, 1. 3rd. ed. Copiar, Córdoba.

SAYAGO, M. 1969. Estudio fitogeográfico del norte de Córdoba. Bol Acad Nac Cienc 46: 123-427.

SCARPA, G. F. 1999. El arrope en el Noroeste Argentino. Ayer una fiesta, hoy un capital. En: GARRIDO ARANDA, A. (Ed.), Los sabores de España y América, pp. 93-139. La Val de Onsera, España.

SCARPA, G. F. 2009. Wild food plants used by the indigenous peoples of the South American Gran Chaco: A general synopsis and intercultural comparison. J Appl Bot Food Qual 83: 90-101.

SCARPA, G. F. 2012. Las plantas en la vida de los criollos del oeste formoseño: medicina, ganadería, alimentación y viviendas tradicionales. Asociación Civil Rumbo Sur, Buenos Aires. 


\section{Saur Palmieri et al. - Especies y prácticas de frutos comestibles en Cerro Colorado}

SÉRSIC, A., A. COCUCCI, S. BENÍTEZ-VIEYRA, A. COSACOV, L. DÍAZ, E. GLINOS, N. GROSSO, C. LAZARTE, M. MEDINA, M. MORÉ, M. MOYANO, J. NATTERO, V. PAIARO, C. TRUJILLO \& P. WIEMER. 2010. Flores del centro de Argentina: una guía ilustrada para conocer 141 especies típicas. Academia Nacional de Ciencias, Córdoba.

SILVETTI, F. \& D. CÁCERES. 1998. Una perspectiva sociohistórica de las estrategias campesinas del noreste de Córdoba, Argentina. Debate Agrar 28: 103-127.

STEVENS, C. J. 2003. An investigation of agricultural consumption and production models for prehistoric and Roman Britain. Environ Archaeol 8: 61-76.

TOLEDO, J. M., A. A. CORREA \& G. BRACAMONTE. 2015. Frutos comestibles nativos de la Provincia de Córdoba, Argentina. Advocatus, Córdoba.

TORRICO CHALABE, J. K. \& C. TRILLO. 2015. Prácticas de manejo, usos y valoración de taxones de Cactaceae en el Noroeste de Córdoba, Argentina. Bonplandia 24: 5-22.

TRILLO, C. 2010. Valoración del Bosque y Uso de las Plantas Silvestres por Parte de los Pobladores del Valle de Guasapampa, Noroeste de la Provincia de Córdoba. Tesis Doctoral, FCEFyN-UNC.

TRILLO, C. 2016. Prácticas modeladoras sobre los paisajes culturales del oeste de la provincia de Córdoba, Argentina. Zonas áridas 16: 86-111.
TRILLO, C., B. ARIAS TOLEDO, L. GALETTO \& S. COLANTONIO. 2010. Persistence of the Use of Medicinal Plants in Rural Communities of the Western Arid Chaco [Córdoba, Argentina]. Open Compl Med J 2: 80-89.

TRILlO, C., S. COLANTONIO \& L. GALETTO. 2014. Perceptions and Use of Native Forests in the Arid Chaco of Córdoba, Argentina. Ethnobotany Research \& Applications 12: 497-510.

TRILlO, C., P. DEMAIO, P, COLANTONIO, S. \& L. GALETTO. 2007. Conocimiento actual de plantas tintóreas por los pobladores del valle de Guasapampa, provincia de Córdoba. Kurtziana 33: 65-71.

VILLAFUERTE, C. 1984. Diccionario de árboles, arbustos y yuyos en el folklore argentino. Plus Ultra, Buenos Aires.

VOLKMANN, L. R. \& N. B. VON MÜLLER. 1999. Trepadoras y apoyantes más comunes de la Sierra Chica, Punilla, Córdoba. Prosopis, Córdoba.

WRIGHT, P. 2003. Preservation or destruction of plant remains by carbonization?. J Archaeol Sci 30: 577 583.

Recibido el 4 de mayo de 2017, aceptado el 7 de agosto de 2017. Editor: Norma Hilgert. 
